\title{
Salvage Radiotherapy for Macroscopic Local Recurrence Following Radical Prostatectomy
}

\author{
Hind Zaine ${ }^{1}$, Benjamin Vandendorpe ${ }^{1}$, Benoit Bataille ${ }^{1}$, Thomas Lacornerie ${ }^{2}$, \\ Jennifer Wallet ${ }^{3}$, Xavier Mirabel ${ }^{1}$, Eric Lartigau ${ }^{1,4}$ and David Pasquier ${ }^{1,4 *}$ \\ ${ }^{1}$ Academic Department of Radiation Oncology, Centre Oscar Lambret, Lille, France, ${ }^{2}$ Department of Medical Physics, \\ Centre O. Lambret, Lille, France, ${ }^{3}$ Department of Biostatistics, Centre O. Lambret, Lille, France, ${ }^{4}$ CRIStAL (Centre de \\ Recherche en Informatique, Signal et Automatique de Lille [Research center in Computer Science, Signal and Automatic \\ Control of Lille] UMR (Unité Mixte de Recherche [joint research center]) 9189, Lille University, Lille, France
}

Introduction: Salvage radiotherapy is the only curative treatment for biochemical progression after radical prostatectomy. Macroscopic recurrence may be found in the

OPEN ACCESS

Edited by:

Amar U. Kishan,

University of California, Los Angeles,

United States

Reviewed by:

Sean P. Collins,

Georgetown University,

United States

Laure Marignol,

Trinity College Dublin, Ireland

*Correspondence:

David Pasquier

d-pasquier@o-lambret.fr

Specialty section:

This article was submitted to

Radiation Oncology,

a section of the journal

Frontiers in Oncology

Received: 19 February 2021 Accepted: 29 March 2021

Published: 15 April 2021

Citation:

Zaine $H$, Vandendorpe $B$, Bataille $B$, Lacornerie $T$, Wallet $J$, Mirabel $X$, Lartigau E and Pasquier D (2021)

Salvage Radiotherapy for Macroscopic Local Recurrence Following Radical Prostatectomy. Front. Oncol. 11:669261. doi: 10.3389/fonc.2021.669261 prostatic bed. The purpose of our study is to evaluate the effectiveness of salvage radiotherapy of the prostate bed with a boost to the area of the macroscopic recurrence.

Material and Methods: From January 2005 to January 2020, 89 patients with macroscopic recurrence in the prostatectomy bed were treated with salvage radiotherapy +/- hormone therapy. The average PSA level prior to radiotherapy was 1.1 $\mathrm{ng} / \mathrm{mL}$ (SD: 1.6). At the time of biochemical progression, $96 \%$ of the patients had a MRI that revealed the macroscopic recurrence, and $58 \%$ had an additional choline PET scan. $67.4 \%$ of the patients got a boost to the macroscopic nodule, while $32.5 \%$ of the patients only underwent radiotherapy of the prostate bed without a boost. The median total dose of radiotherapy was 70 Gy (Min.: 60 - Max.: 74). The most commonly-used regimen was radiotherapy of the prostatectomy bed with a concomitant boost. $48 \%$ of the patients were concomitantly treated with hormone therapy.

Results: After a median follow-up of 53.7 months, 77 patients were alive and 12 had died, of which 4 following metastatic progression. The 5-year and 8-year survival rates (CI95\%) are, respectively, 90.2\% (78.9-95.6\%) and 69.8\% (46.4-84.4\%). The 5-year biochemical progression-free survival rate (C195\%) is $50.8 \%$ (36.7-63.3). Metastatic recurrence occurred in $11.2 \%$ of the patients. We did not find any statistically significant impact from the various known prognostic factors for biochemical progression-free survival. No toxicity with a grade of $>$ or $=$ to 3 was found.

Conclusions: Our series is one of the largest published to date. Salvage radiotherapy has its place in the management of patients with biochemical progression with local recurrence in the prostate bed, with an acceptable toxicity profile. The interest of the boost is to be evaluated in prospective trials.

Keywords: prostate cancer, macroscopic recurrence, salvage radiotherapy, boost, post-therapeutic toxicity 


\section{HIGHLIGHTS}

- Salvage radiotherapy of the prostatectomy bed usually remains the only curative treatment for recurrence after prostatectomy for prostate cancer.

- Radiation oncologists are increasingly faced with macroscopic disease detected in the prostatectomy bed.

- There is no consensus and so there is considerable variability in the management of this category of patients.

- We present one of the largest series of patients with macroscopic recurrence treated by radiotherapy to date.

- Five years after radiotherapy, around half of the patients presented with a new relapse.

- A boost to the recurrence did not influence relapse free survival and toxicity was low.

- The interest of the boost is evaluated in prospective trials currently.

\section{INTRODUCTION}

Radical prostatectomy is an effective curative therapy and is widely used for localized prostate cancers. However, 15 to $40 \%$ of operated patients develop biochemical progression within five years after surgery $(1,2)$.

Salvage radiotherapy of the prostatectomy bed usually remains the only curative therapy indicated from a PSA level > $0.2 \mathrm{ng} / \mathrm{ml}$. The effectiveness of this therapy depends on the PSA level, and some studies specify that the treatment is more effective when the pre-treatment PSA is less than $0.5 \mathrm{ng} / \mathrm{mL}$ $(3,4)$.

The benefits of additional hormone therapy vary depending on the pathological characteristics and make it possible to prolong metastasis-free survival $(5,6)$.

With the progress achieved in imaging (prostate MRIs, choline PET scans) and more recently PSMA PET CT, which is sensitive at PSA levels of less than $1 \mathrm{ng} / \mathrm{mL}$ or even $0.5 \mathrm{ng} / \mathrm{mL}$ $(7,8)$, radiation oncologists are increasingly faced with occurrences of biochemical progression with macroscopic disease found in the prostatectomy bed.

A 66 Gy dose, which is commonly used to treat biochemical progression, may be insufficient in cases of macroscopic recurrence, and increasing the doses applied to these recurrences is common.

To date, there is no consensus with regard to the application of a boost (target volumes, techniques, total dose, fractionation, etc.) and so there is considerable variability in the management of this category of patients with macroscopic recurrence.

The purpose of this analysis is to study this category of patients with macroscopic recurrence in the prostatectomy bed; to evaluate, retrospectively, the effectiveness of salvage radiotherapy with boost to the recurrence; and lastly, to define what place hormone therapy has in this situation.

\section{MATERIAL AND METHODS}

After having obtained the patients consent to the use of their data, we conducted a retrospective study of the patients treated by radiotherapy of the prostate bed at the Centre Oscar Lambret between January 2005 and January 2020 and who had an identified macroscopic recurrence. All patients treated consecutively were included.

A macroscopic local recurrence was defined by a relapse in prostatectomy bed visible on MRI and/or CT scan and/or choline PET and/or accessible to clinical examination by digital rectal examination.

89 patients were included; their average age when diagnosed was 61.3 years $(\mathrm{SD}=5.7)$. The average pre-operation PSA level was $9.4 \mathrm{mg} / \mathrm{mL}(\mathrm{SD}=4.9)$. The surgical stage according to AJCC TNM, 8th Edition, was, for 36\%, stage pT3a; for 20\%, pT3b; and for $20 \%$, pT2c. Lymph node dissection was performed in $67 \%$ of the patients and came back negative ( $\mathrm{pN} 0$ ) for all of them. The Gleason score was 7 in $77 \%$ of the cases, less than 7 in $14 \%$ of the cases, and greater than 7 in $8.9 \%$ of the cases. The resection margin was R0 in $51 \%$ of the patients. The post-operation PSA nadir could not be measured in $87 \%$ of the patients. $53 \%$ of the patients developed post-operation urinary complications, mostly grade 1 ( $40 \%$ of the operated patients) (Table 1).

The median time to post-prostatectomy biochemical progression was 2.3 years (Min.: 0.1-Max.: 18.9)

Multiparameter magnetic resonance imaging was performed in all except four patients who had a prostate bed nodule that was palpable on digital rectal examination and visible in the pelvic computed tomography. The median size of the prostate bed nodule was $9.5 \mathrm{~mm}$ (Min.: 2-Max.: 35). The recurrence was most often localized in the perianastomotic position (38.8\%). 58\% of

TABLE 1 | Patient characteristics.

\begin{tabular}{|c|c|c|}
\hline Radical prostatectomy & \multicolumn{2}{|c|}{ Population N = 89} \\
\hline \multicolumn{3}{|l|}{ pTNM: T (MD = 5) } \\
\hline pT2a & 7 & $8 \%$ \\
\hline pT2b & 13 & $15 \%$ \\
\hline pT2c & 17 & $20 \%$ \\
\hline рT3a & 30 & $36 \%$ \\
\hline pT3b & 17 & $20 \%$ \\
\hline \multicolumn{3}{|l|}{ pTNM: N (MD = 3) } \\
\hline NO & 58 & $67 \%$ \\
\hline Nx (no lymph node dissection) & 28 & $33 \%$ \\
\hline \multicolumn{3}{|l|}{ Gleason Score (MD = 3) } \\
\hline Gleason $<=7$ & 78 & $91 \%$ \\
\hline Gleason $>=8$ & 8 & $9 \%$ \\
\hline \multicolumn{3}{|l|}{ Resection margin (MD = 5) } \\
\hline RO & 43 & $51 \%$ \\
\hline $\mathrm{R} 1$ & 41 & $49 \%$ \\
\hline \multicolumn{3}{|l|}{ Post-op PSA } \\
\hline Not measurable & 77 & $87 \%$ \\
\hline Measurable & 12 & $13 \%$ \\
\hline \multicolumn{3}{|c|}{ Postoperative urinary toxicities (MD=2) } \\
\hline Grade 1 & 35 & $40.2 \%$ \\
\hline Grade 2 & 11 & $12.6 \%$ \\
\hline
\end{tabular}

MD, missing data. 
the patients had had a choline PET scan, which showed hyperfixation at the macroscopic nodule in $21 \%$ of cases. Pelvic lymph node recurrence was found in $6 \%$ of the patients. A biopsy of the prostate bed nodule was performed in $20 \%$ of the patients and was positive for $10 \%$ of the patients (Table 2).

$15 \%$ of the patients had been treated prior to the salvage radiotherapy: $11 \%$ had had hormone therapy, $2 \%$ had had chemotherapy in combination with hormone therapy (Rising PSA clinical trial) and $2 \%$ had had stereotactic pelvic lymph node radiotherapy in combination with hormone therapy.

TABLE 2 | Characteristics of the macroscopic recurrence following radical prostatectomy.

\begin{tabular}{|c|c|c|}
\hline \multirow{2}{*}{$\begin{array}{l}\text { Characteristics } \\
\text { Location of the macroscopic recurrence on the MRI }(M D=4)\end{array}$} & \multicolumn{2}{|c|}{$\begin{array}{l}\text { Population } \\
\mathbf{N}=89\end{array}$} \\
\hline & & \\
\hline Perianastomotic & 33 & $38.8 \%$ \\
\hline Periurethral & 5 & $5.8 \%$ \\
\hline Residual SV or SV bed & 10 & $11.7 \%$ \\
\hline Other & 37 & $43.5 \%$ \\
\hline \multicolumn{3}{|c|}{$\begin{array}{l}\text { Size of the macroscopic recurrence on the MRI, in } \mathrm{mm} \\
(M D=13)\end{array}$} \\
\hline Median - (Range) & 9.5 & $(2-35)$ \\
\hline Mean - SD & 11.3 & 6.6 \\
\hline \multicolumn{3}{|l|}{ PET scan } \\
\hline Done & 52 & $58 \%$ \\
\hline Non-hypermetabolic recurrence & 33 & $37 \%$ \\
\hline Hypermetabolic recurrence & 19 & $21 \%$ \\
\hline \multicolumn{3}{|l|}{ Biopsy of the recurrence } \\
\hline Done & 18 & $20 \%$ \\
\hline Negative & 9 & $10 \%$ \\
\hline Positive & 9 & $10 \%$ \\
\hline
\end{tabular}

$M D$, Missing data; $L R$, Local recurrence.
The average PSA level prior to starting radiotherapy was 1.1 $\mathrm{ng} / \mathrm{mL}(\mathrm{SD}=1.6)$. The average PSA doubling time was 10.7 months $(\mathrm{SD}=11.7)$.

The radiotherapy techniques used were intensity-modulated radiotherapy in $77.5 \%$ of the patients and the three-dimensional technique in $22.4 \%$ of them.

The median total dose of radiotherapy was 70 Gy (Min.: 60 Max.: 74); the median dose applied to the prostate bed was $66 \mathrm{~Gy}$ (Min.:50- Max.:66.6). The median boost fractionation was 2.1 Gy/fraction (Min.: 1.8 - Max.: 6). The median duration of the radiotherapy was 48 days.

The most commonly-used regimen was radiotherapy of the prostatectomy bed with a concomitant supplementary dose (boost) to the macroscopic recurrence (Figures 1A, B). $67.4 \%$ of the patients treated by salvage radiotherapy received a boost to the macroscopic nodule, applied concomitantly with intensity modulation in $56.66 \%$ of them, and sequentially in $43.33 \%$ of them. $32.6 \%$ of the patients had radiotherapy of the prostate bed alone with no boost. $25 \%$ of patents underwent pelvic lymph node irradiation (Table 3 ).

We compared the two groups (with boost and without boost) in terms of median follow-up, baseline PSA, size of the macroscopic recurrence, the use or not of ADT and the choice of radiotherapy technique. The two groups were well balanced except for the technique and follow up. In the boost group, IMRT was used more often $(90 \%$ vs $51.7 \%, \mathrm{p}<0.001)$ and the median follow up was shorter: 45 months (40-54 months) vs 61.4 months (51-72 months), $\mathrm{p}=0.03$.

We recorded the acute toxicities (during the radiotherapy and within three months post-treatment) and the delayed ones (more than three months after the end of the treatment). These toxicities were graded on the CTCAE scale, version 4.03.
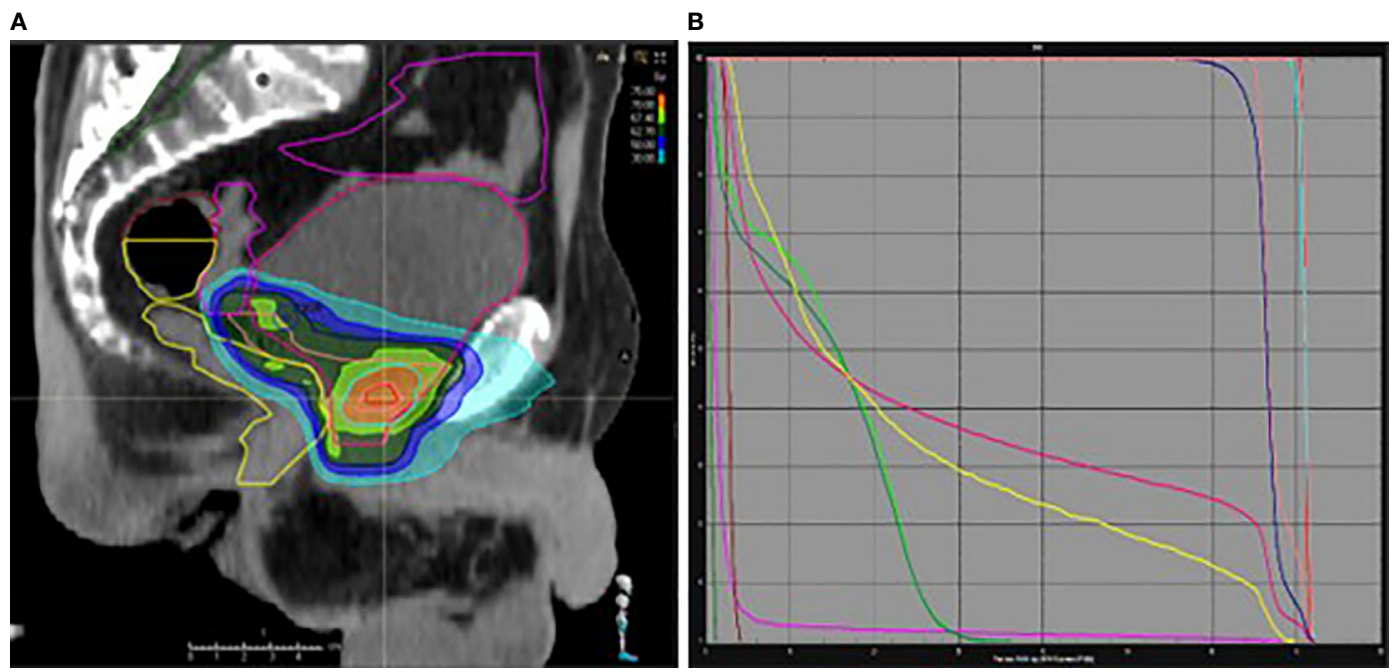

FIGURE 1 | (A, B) Intensity Modulated Radiation Therapy of the prostatectomy bed (66 Gy) with a concomitant boost to the macroscopic recurrence (70.95 Gy). Sagittal view (A) and dose volume histogram (B). Pink and blue: prostatic bed and macroscopic recurrence CTV and PTV; yellow: rectum; red: bladder; green: femoral heads. 
TABLE 3 | Radiotherapy treatment methods.

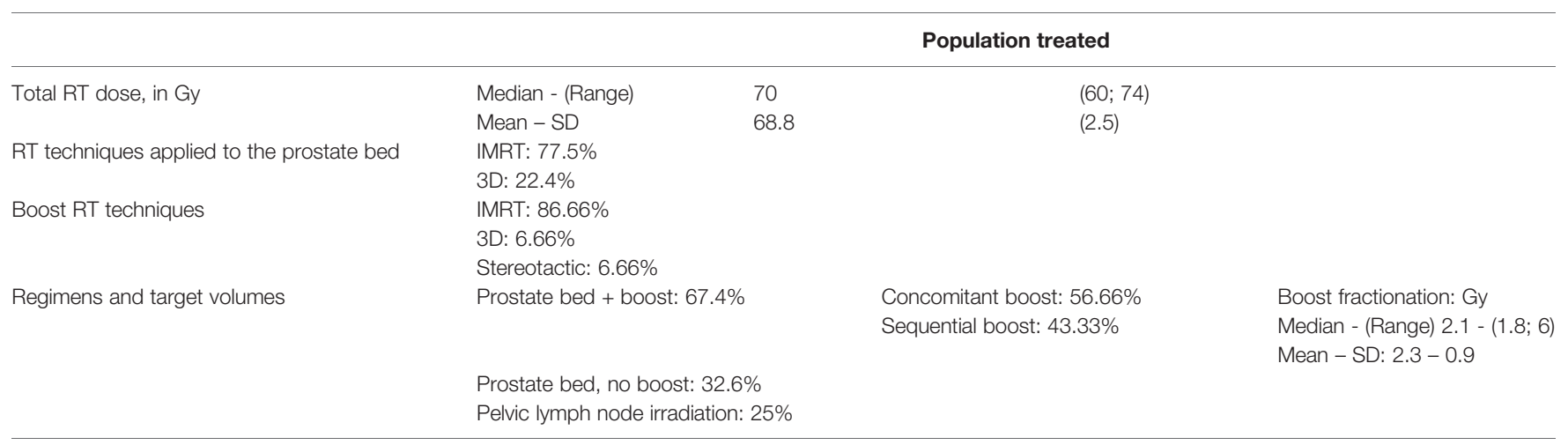

RT, Radiotherapy; Boost, supplementary dose; IMRT, intensity-modulated radiotherapy; 3D, three-dimensional radiotherapy; Fr, fractionation.

$48 \%$ of the patients had hormone therapy in combination with the radiotherapy, most often for a short period of time (6 months) (45\%). Post-radiotherapy patient follow-up was carried out alternatively with the urologists, on a quarterly basis in the first year and then every six months, with a PSA screening performed prior to each consultation.

Remission is defined by a post-radiotherapy PSA nadir level less than the pre-radiotherapy PSA level. There being no consensual definition about biochemical progression after salvage radiotherapy, we opted for two definitions in our study: PSA $>0.2 \mathrm{ng} / \mathrm{mL}$ (definition 1) and post-radiotherapy PSA > PSA nadir $+0.5 \mathrm{ng} / \mathrm{mL}$ (definition 2). The latter definition was used in a recent retrospective study (9). Rising PSA was confirmed by two screenings one month apart.

Clinical recurrence is defined by the detection of a local, pelvic lymph node, recurrence or distant metastatic recurrence on imaging studies. A second imaging may be performed at the doctor's discretion.

\section{Statistical Analysis}

Biochemical progression-free survival (main criterion) with no metastatic or local recurrence and overall survival (secondary criteria) were estimated using the Kaplan-Meier method from the radiotherapy start date.

The prognostic value of the PSA level at the start of the treatment and the prognostic value of the boost with regard to biochemical progression-free survival were assessed using Cox regression models. The threshold of significance was set at $5 \%$.

The software used was Stata v15.0 (StataCorp. 2009. Stata Statistical Software: Release 11. College Station, TX: StataCorp LP).

\section{RESULTS}

Post-radiotherapy remission was achieved in $93 \%$ of the patients, $79 \%$ of whom had a PSA nadir below $0.1 \mathrm{ng} / \mathrm{mL}$.

The patients' follow-up, calculated using the Kaplan-Meier method, was 53.7 months (42.8-59.4 months). As of this followup, 77 patients were alive and 12 had died, of which 4 following metastatic progression. The 5-year (CI95\%) and 8-year survival rates were, respectively, $90.2 \%(78.9-95.6 \%)$ and $69.8 \%(46.4-$ 84.4\%) (Figure 2).

The median biochemical progression-free survival (CI95\%) were 60.1 months (39.3 - 73.0) and 73.0 months (50.7 - 88.2), according to PSA $>0.2 \mathrm{ng} / \mathrm{mL}$ (Definition 1) or post-RT PSA nadir $+0.5 \mathrm{ng} /$ $\mathrm{mL}$ (Definition 2), respectively. The 5-year biochemical progression-free survival rates (CI95\%) were, respectively, 50.8\% (36.7 - 63.3) (Definition 1) and 56.6\% (42.7 - 68.2) (Definition 2) (Table 4, Figure 3).

The average time between the radiotherapy and the biochemical progression (Definition 2 ) was 2.8 years $(\mathrm{SD}=1.9$ ).

Metastatic recurrence occurred in $11.2 \%$ of the patients, with $7 \%$ of them presenting with bone metastasis.

We performed an analysis of the impact of the prognostic and therapeutic factors (tumoral stage, post-op Gleason score, resection margins, pre-RT PSA level, PSA kinetics, size of the macroscopic recurrence, boost to the macroscopic recurrence, hormone therapy, etc.) on the biochemical progression-free survival rate. None of these factors was significantly associated with biochemical progression-free survival in univariate analysis. Furthermore, we did not observe any significant heterogeneity of Boost effect in terms of biochemical progression-free survival according to the status of hormonotherapy.

With regard to the tolerance of the radiotherapy, $62 \%$ of the patients had acute urinary toxicity, of grade 1 in $47 \%$ of the cases. $53 \%$ of the patients developed delayed urinary toxicity of which $40 \%$ were grade 1 . The side effects were mostly irritative signs of the lower urinary tract (pollakiuria, urgency). Late hematuria occurred in 4 patients in the Boost group and was grade 1 and 2 .

$20 \%$ and $8 \%$, respectively, developed acute and delayed digestive toxicity. Escalating the radiotherapy dose to the macroscopic nodule in the prostate bed did not seem to increase either the risk or the severity of the acute or delayed urinary and digestive toxicity $(\mathrm{p}>0.5)$.

\section{DISCUSSION}

Our work is a descriptive retrospective study of a series of 89 patients with a macroscopic recurrence in the prostate bed and who underwent radiation therapy at the Oscar Lambret Centre. 


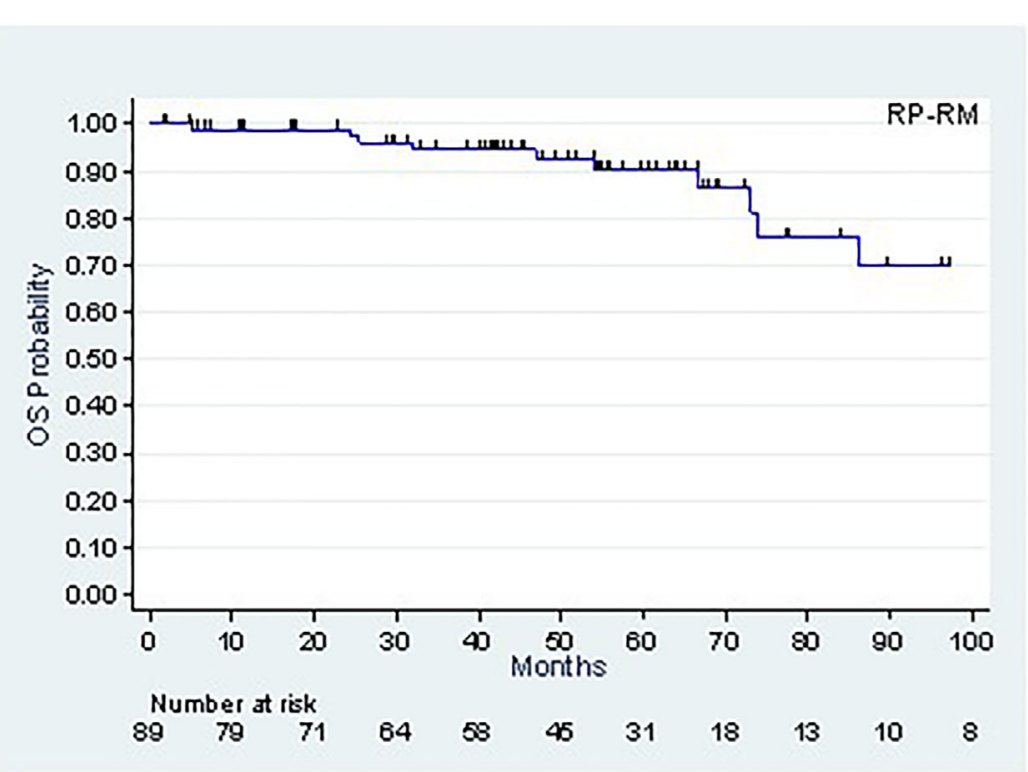

FIGURE 2 | Overall survival.

TABLE 4 | Biochemical progression-free survival.

\section{Characteristics}

Survived with no recurrence

Number of progressions or deaths

Median (months) (Cl95\%)

5 -year rate (\%) (CI95\%)

8 -year rate (\%) (CI95\%)

2 biochemical progressions, $P S A>0.2 \& 5$ deaths with no prior biochemical progression.

${ }^{(2)} 28$ biochemical progressions, post-RT PSA nadir +0.5 \& 5 deaths with no prior biochemical progression.

\section{According to post-RT PSA nadir+ 0.5 (Def 2)}

$\begin{array}{lr}37^{(1)} & \\ 60.1 \text { months } & (39.3-73.0) \\ 50.8 \% & (36.7-63.3) \\ 16.4 \% & (3.3-38.4)\end{array}$

$33^{(2)}$
73.0 months
$56.6 \%$
$18.8 \%$

$(50.7-88.2)$

$(42.7-68.2)$

$(3.8-42.4)$

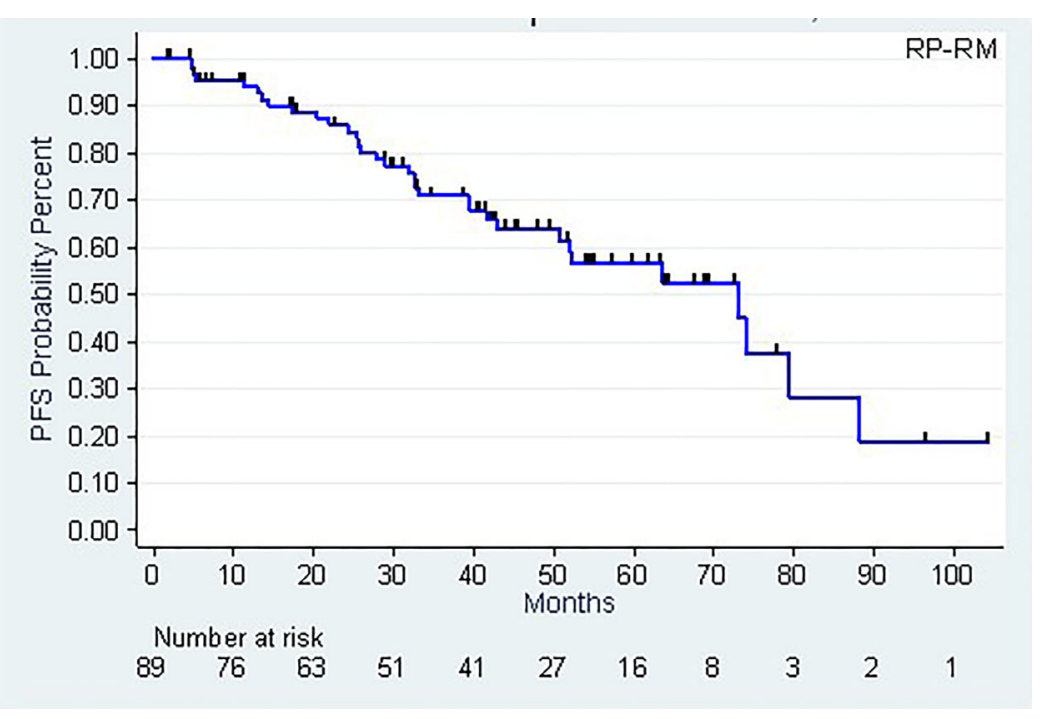

FIGURE 3 | Biochemical progression-free survival (PSA nadir + $0.5 \mathrm{ng} / \mathrm{mL}$ ). 


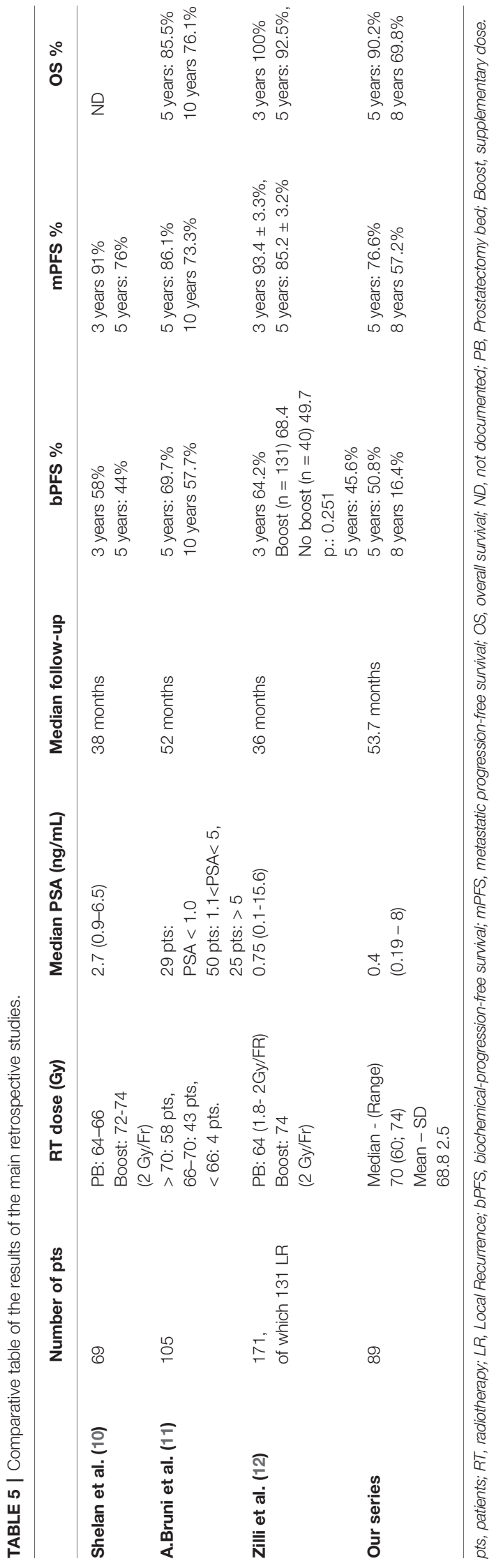

It is one of the series with the largest number of participants published to date (10-12) (Table 5).

Salvage radiation is the only potentially curative therapy for biological progression after radical prostatectomy. It is associated with an improved biochemical progression-free survival rate, an improved metastatic progression-free survival rate, and an improved survival rate overall (13). Several studies have shown that the efficiency of salvage RT is highly dependent on the prostate-specific antigen (PSA) level prior to radiotherapy (14).

Magnetic resonance imaging appears to be one of the best diagnostic tools for detecting local recurrence when the PSA level is below $<1 \mathrm{ng} / \mathrm{mL}$ (8). Thus, radiation oncologists are increasingly faced with occurrences of macroscopic recurrences in the prostate bed. In our series, $58 \%$ of the patents with a macroscopic nodule visible under MRI have a PSA less than or equal to $0.5 \mathrm{ng} / \mathrm{mL}$. Choline PET is associated with improved sensitivity and specificity on lymph node recurrences (15). PSMA PET CTs are more sensitive and can be suggested for patients whose PSA level is less than $0.5 \mathrm{ng} / \mathrm{mL}(16,17)$.

The PSA level prior to salvage radiotherapy is a prognostic factor in the radiotherapy response. In a meta-analysis by Ohri et al, a 1 $\mathrm{ng} / \mathrm{mL}$ increase in the pre-RT PSA reduces 5-year biochemical progression-free survival by $18.3 \%$ (CI of $95 \%$ : 10.4\%-26.3\%) (18). In our series, we did not find any statistically significant correlation between the pre-RT PSA level and the biochemical progression-free survival rate, though this may have been due to the hormone treatment prescribed for about half of the patients.

The optimal dose indicated to treat microscopic disease in the prostate bed is 64-66 Gy $(19,20)$, which may be insufficient if macroscopic disease is found in the bed. Increasing the dose in this category of patients may be necessary to get therapeutic results comparable to those of patients with no macroscopic disease.

In our analysis, the 5-year biochemical progression-free survival rate was 50.8\% ((CI95\%): 36.7-63.3); the 5-year metastatic progression-free survival rate was $76.6 \%$ ((CI95\%): 62.7-85.9). Our results are very similar to those of the retrospective study by Shelan et al. (10); all of the patients in that study were treated uniformly with image-guided doseescalated RT to the macroscopic recurrence: 3 to 5 -year biochemical progression-free survival was $58 \%$ and $44 \%$, respectively, and 3 to 5 -year clinical survival was $91 \%$ and $76 \%$.

In our analysis, we did not find any statistically significant difference between radiotherapy with or without boost, with regard to biochemical progression-free survival; nor did they in the retrospective study by A. Bruni et al. (11) in which no statistical advantage was found in the group receiving the increased dose (>70 Gy) with regard to OS or to mPFS. In another study by Zilli et al. (12), there is no significant difference in 3-year biochemical-progression-free survival between standard prostate bed therapy targeting a microscopic disease and boosted treatment if a nodule is identified by MRI ( $74 \mathrm{~Gy}$ : 68.4 months $\pm 4.6 / 64$ Gy: 49.7 months \pm 10.0 ).

These various results raise the question of whether there is any interest in escalating the dose to the macroscopic nodule; however, in these various studies, as in ours, the hormone therapy could have masked a potential benefit. In our study, 
the increase in the dose to the macroscopic nodule was also limited and might explain these negative results.

With regard to post-radiotherapy toxicity, a prospective study that assesses the escalated dose of post-operation radiotherapy (64Gy vs.70Gy), in the absence of any detectable local recurrence, is the SAKK 09/10 study. This study showed low, grade 2 and grade $3 \mathrm{U}$ and GI toxicity rates with minor impact on urinary quality of life (21). In the Ohri series (18), late GI and GU toxicity increased with salvage radiotherapy dose by $1.2 \%$ per Gy $(\mathrm{p}=0.012)$ and $0.7 \%$ per $\mathrm{Gy}(\mathrm{p}=0.010)$, respectively. In our series, escalating the radiotherapy dose to the macroscopic nodule on the prostate bed did not significantly increase the risk and severity of acute and delayed post-radiation toxicity.

Due to the lack of standard management of this category of patients, a prospective study must be undertaken to better define the place of dose escalation, radiotherapy regimens, as well as that of hormone therapy, and thus to standardize care. In this regard, a prospective study, “The MAPS Trial” (NCT01411345) is underway. It assesses dose escalation in light of the recurrence detected in post-prostatectomy MRI (68 Gy, in 2 Gy/fraction to the prostatectomy site and concomitant boost of $2.25 \mathrm{~Gy} /$ fraction, for a total dose of $76.5 \mathrm{~Gy}$ ).

\section{CONCLUSION}

Salvage radiotherapy has its place in the management of patients with biochemical progression with local recurrence in the

\section{REFERENCES}

1. Han M, Pound CR, Potter SR, Partin AW, Epstein JI, Walsh PC. Isolated local recurrence is rare after radical prostatectomy in men with gleason 7 prostate cancer and positive surgical margins: therapeutic implications. J Urol (2001) 165:864-6. doi: 10.1016/S0022-5347(05)66545-7

2. Thompson IM, Valicenti RK, Albertsen P, Davis BJ, Goldenberg SL, Hahn C, et al. Adjuvant and salvage radiotherapy after prostatectomy: AUA/ASTRO Guideline. J Urol (2013) 190:441-9. doi: 10.1016/j.juro.2013.05.032

3. Freedland SJ, Rumble RB, Finelli A, Chen RC, Slovin S, Stein MN, et al. Adjuvant and salvage radiotherapy after prostatectomy: american society of clinical oncology clinical practice guideline endorsement. J Clin Oncol (2017) 32:3892-8. doi: 10.1200/JCO.2014.58.8525

4. Guidelines NCCN. (2018). https://www.nccn.org/professionals/.

5. Shipley WU, Seiferheld W, Lukka HR, Major PP, Heney NM, Grignon DJ, et al. Radiation with or without Antiandrogen Therapy in Recurrent Prostate Cancer. NRG Oncology RTOG. N Engl J Med (2017) 376(5):417-28. doi: 10.1056/NEJMoa1607529

6. Carrie C, Magné N, Burban-Provost P, Sargos P, Latorzeff I, Lagrange JL, et al. Short-term androgen deprivation therapy combined with radiotherapy as salvage treatment after radical prostatectomy for prostate cancer (GETUGAFU 16): a 112-month follow-up of a phase 3, randomised trial. Lancet Oncol (2019) 20(12):1740-9. doi: 10.1016/S1470-2045(19)30486-3

7. Umbehr MH, Muntener M, Hany T, Sulser T, Bachann LM. The role of 11ccholine and 18f-fluorocholine positron emission tomography (PET) and PET/ CT in prostate cancer: a systematic review and meta-analysis. Eur Urol (2013) 64(1):106-17. doi: 10.1016/j.eururo.2013.04.019

8. Buergy D, Sertdemir M, Weidner A, Shelan M, Lohr F, Wenz F, et al. Detection of local recurrence with 3-Tesla MRI after radical prostatectomy: a useful method for radiation treatment Planning. In Vivo (2018) 32(1):125-31. doi: 10.21873/invivo.11214 prostate bed, with an acceptable toxicity profile. The interest of the boost is to be evaluated in prospective trials.

\section{DATA AVAILABILITY STATEMENT}

The raw data supporting the conclusions of this article will be made available by the authors, without undue reservation.

\section{ETHICS STATEMENT}

Ethical review and approval was not required for the study on human participants in accordance with the local legislation and institutional requirements. Written informed consent for participation was not required for this study in accordance with the national legislation and the institutional requirements.

\section{AUTHOR CONTRIBUTIONS}

DP and HZ designed the study. HZ performed the data collection. DP, BV, BB, TL, XM and EL performed the patients' recruitment and the follow-up. JW performed the statistical analysis. HZ wrote the original draft. DP supervised the project. All authors helped revising and editing the manuscript.

9. Shelan M, Abo-Madyan Y, Welzel G, Bolenz C, Kosakowski J, Behnam N, et al. Dose-escalated salvage radiotherapy after radical prostatectomy in high risk prostate cancer patients without hormone therapy: outcome, prognostic factors and late toxicity. Radiat Oncol (2013) 27(8):276. doi: 10.1186/1748-717X-8-276

10. Shelan M, Odermatt S, Bojaxhiu B, Nguyen DP, Thalmann GN, Aebersold DM, et al. Disease Control With Delayed Salvage Radiotherapy for Macroscopic Local Recurrence Following Radical Prostatectomy. Front Oncol (2019) 9:12. doi: 10.3389/fonc.2019.00012

11. Bruni A, Ingrosso G, Trippa F, Di Staso M, Lanfranchi B, Rubino L, et al. Macroscopic locoregional relapse from prostate cancer: which role for salvage radiotherapy. Clin Trans Oncol (2019) 21(11):1532-37. doi: 10.1007/s12094019-02084-0

12. Zilli T, Jorcano S, Peguret N, Caparrotti F, Hidalgo A, Khan HG, et al. Results of Dose-adapted Salvage Radiotherapy After Radical Prostatectomy Based on an Endorectal MRI Target Definition Model. Am J Clin Oncol (2017) 40 (2):194-9. doi: 10.1097/COC.0000000000000130

13. King CR. The timing of salvage radiotherapy after radical prostatectomy: a systematic review. Int J Radiat Oncol Biol Phys (2012) 84(1):104-11. doi: 10.1016/j.ijrobp.2011.10.069

14. Stephenson AJ, Scardino PT, Kattan MW, Pisansky TM, Slawin KM, Klein EA, et al. Predicting the outcome of salvage radiation therapy for recurrent prostate cancer after radical prostatectomy. J Clin Oncol (2009) 25:2035-41. doi: 10.1200/JCO.2006.08.9607

15. Sandgren K, Westerlinck P, Jonsson JH, Blomqvist L, Thellenberg Karlsson C, Nyholm $\mathrm{T}$, et al. Imaging for the detection of locoregional recurrences in biochemical progression after radical prostatectomy-a systematic review. Eur Urol Focus (2017) 5(4):550-60. doi: 10.1016/j.euf.2017.11.001

16. Annunziata S, Pizzuto DA, Treglia G. Diagnostic Performance of PET Imaging Using Different Radiopharmaceuticals in Prostate Cancer According to Published Meta-Analyses. Cancers (Basel) (2020) 12(8):2153. doi: $10.3390 /$ cancers 12082153 
17. Mottet N, Cornford P, van den Bergh RCN, Briers E, De Santis M, et al. EAU EANM - ESTRO - ESUR - ISUP - SIOG Guidelines on Prostate Cancer. (2021). Available at: https://uroweb.org/.

18. Ohri N, Dicker AP, Trabulsi EJ, Showalter TN. Can early implementation of salvage radiotherapy for prostate cancer improve the therapeutic ratio? A systematic review and regression meta-analysis with radiobiological modelling. Eur J Cancer (2012) 48(6):837-44. doi: 10.1016/j.ejca.2011.08.013

19. Cox JD, Gallagher MJ, Hammond EH, Kaplan RS, Schellhammer PF. Consensus statements on radiation therapy of prostate cancer: guidelines for prostate re-biopsy after radiation and for radiation therapy with rising prostate-specific antigen levels after radical prostatectomy. American society for therapeutic radiology and oncology consensus panel. J Clin Oncol (1999) 17:1155. doi: 10.1200/JCO.1999.17.4.1155

20. Cornford P, Bellmunt J, Bolla M, Briers E, De Santis M, Gross T, et al. EAUESTRO-SIOG guidelines on prostate cancer. part II: treatment of relapsing, metastatic, and castration-resistant prostate cancer. Eur Urol (2017) 71 (4):630-42. doi: 10.1016/j.eururo.2016.08.002
21. Ghadjar P, Hayoz S, Bernhard J, Zwahlen DR, Hölscher T, Gut P, et al. Acute toxicity and quality of life after dose-intensified salvage radiation therapy for biochemically recurrent prostate cancer after prostatectomy: first results of the randomized trial SAKK 09/10. J Clin Oncol (2017) 33:4158-66. doi: 10.1200/ JCO.2015.63.3529

Conflict of Interest: The authors declare that the research was conducted in the absence of any commercial or financial relationships that could be construed as a potential conflict of interest.

Copyright (ㄷ 2021 Zaine, Vandendorpe, Bataille, Lacornerie, Wallet, Mirabel, Lartigau and Pasquier. This is an open-access article distributed under the terms of the Creative Commons Attribution License (CC BY). The use, distribution or reproduction in other forums is permitted, provided the original author(s) and the copyright owner(s) are credited and that the original publication in this journal is cited, in accordance with accepted academic practice. No use, distribution or reproduction is permitted which does not comply with these terms. 